\title{
Histological Structure of the Varanus Salvator Kidney
}

\author{
Ida Khoirunnisa' \\ Departement of Biology Education, Faculty Science and Technology, State Islamic University of Sunan Kalijaga Yogyakarta \\ Email: idakhoirunnisa99@gmail.com
}

\begin{abstract}
Varanus salvator is known as the monitor lizard. This animal is a subspecies of endemic Indonesian monitor lizards which is only found in Java, Bali and Nusa Tenggara (except Timor Island). This study aims to determine the histological structure of the monitor lizard (Varanus salvator). The research was carried out for two months starting from September 2019 to October 2019 at the Animal Physics Laboratory and Zoology of UIN Sunan Kalijaga. The method used is the paraffin method. The results of the study were analyzed in a comparative descriptive manner by observation through a microscope and then taken using a camera. Based on the results of studies lizards (Varanus salvator) have distal convoluted tubule, proximal convoluted tubule, glomerulus, medullary ray and bowman's capsule.
\end{abstract}

Keyword: Histology, kidney, Varanus salvator

\section{INTRODUCTION}

Indonesia is a tropical region that is influenced by two continents, namely Asia and Australia, thus making this region rich in biodiversity of flora and fauna. Despite this scientific information about biodiversity has not been widely published in Indonesia, especially regarding reptiles (Mahfud, 2014). Reptiles are one of the many fauna found in the territory of Indonesia. Indonesia ranks third as the country with the highest reptile wealth in the world. More than 600 types of reptiles are found in Indonesia (Bappenas, 1993). This reptile has long been used, and even has become a high-value economic commodity. Utilization of reptiles is usually as pets. However, reptiles are consumed and used as medicines which have developed to various countries. Even in the last two decades Indonesia is known as one of the largest reptile exporters in the world (Soehartono and Mardiastuti, 2003).

Canto (2007) in Mahfud et al (2017) said that Varanus salvator bivittatus is a subspecies of Varanus salvator or known as water lizards. This animal is a subspecies of endemic Indonesian monitor lizards which is only found in Java, Bali and Nusa Tenggara (except Timor Island). Gumilang (2003) in Mahfud et al (2017) said that water lizards are included in the Appendix II category in the CITES list (The Convention on International Trade in Endangered Species of Wild Fauna and Flora) This means that water lizards can be traded on international markets with a quota that is has been established. Survey results show that more than one million $V$. salvator lizards are taken from nature every year to be killed and skinned, with the largest number coming from Indonesia, especially Sumatra and Kalimantan. If $V$. salvator exploitation continues, it will result in a decline in the population of these animals in the wild. and does not rule out the possibility of $\mathrm{V}$. salvator will be categorized in Appendix I of CITES as well as on V. komodoensis.

In Indonesia, water lizards are not yet included in the list of protected animals. However, if not carried out various studies that support efforts to conserve water lizards, these animals will be endangered in the future. Therefore, this study aims to examine the anatomical and histological morphology of kidney organs in water lizards (Varanus salvator).

\section{MATERIAL AND METHODS}

This study uses adult monitor lizards obtained from the river in the Bantul area. The method used is the paraffin method 5 which is done by making histological preparations, making preparations covering several processes namely surgery, fixation, trimming, dehydration, clearing, infiltration, embedding, sectioning, staining, and mounting (Suntoro, 1983). The results of the renal histology preparations (Varanus salvator) were analyzed in a comparative descriptive manner.

\section{RESULTS AND DISCUSSION}

Based on research that has been done, there are three histological preparations, namely histology of the anterior, middle, and posterior kidneys. The anatomical features and preparations for renal histology are as follows.

Based on research that have been made on monitor lizards that are associated with the kidney excretion system there are right and left kidneys. Kidneys in vertebrates in general amount to a pair. Each kidney consists of cortex and medulla, with the functional unit 
being a nephron consisting of renal corpuscles (Malpighi bodies), glomerulus and tubules. The kidneys are located in the caudodorsal abdomen. The kidneys play a role in the excretory system to excrete metabolic waste products, control the volume and composition of body fluids, regulate water balance, electrolytes, osmolality of body fluids, regulate arterial pressure, and regulate acid base balance. In addition, the kidneys also play a role in gluconeogenesis and hormone excretion (Guyton \& Hall 2006).

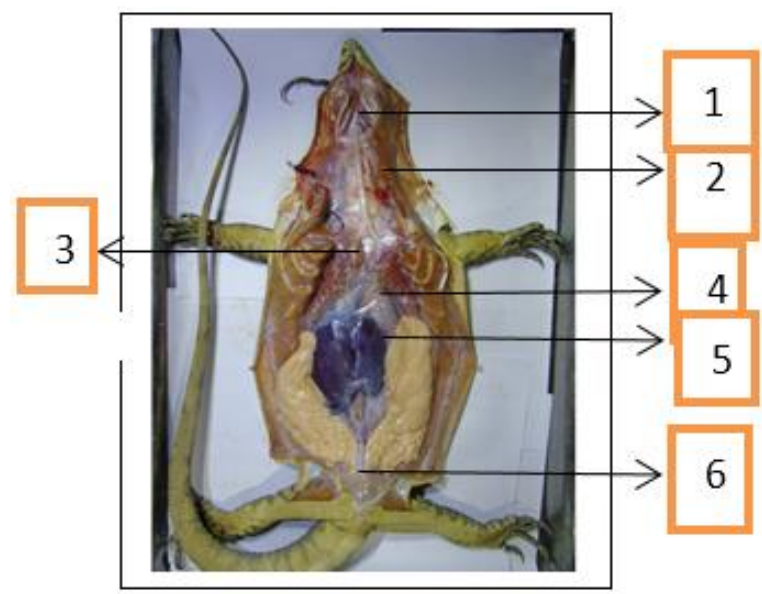

Figure 1. Anatomical Structure of Varanus salvator ; Esophagus (1), trachea (2), lungs (3), gastric (4), heart (5), cloaca (6).

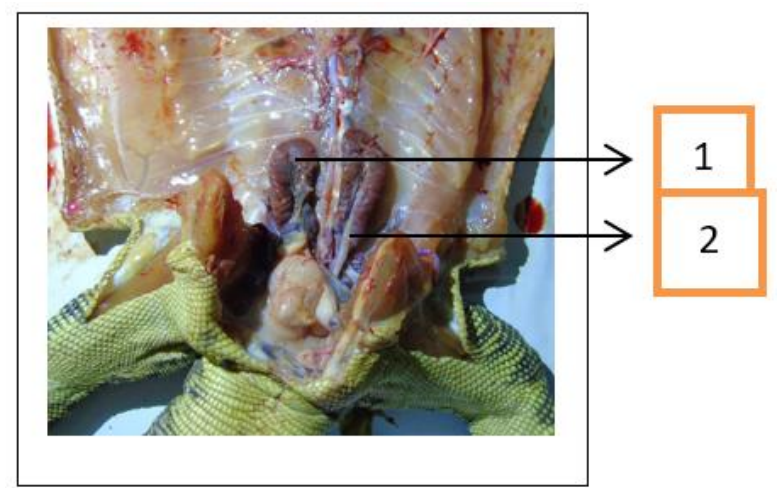

Figure 2. Kidney anatomi of Varanus salvator; Right kidney (1), Left kidney (2).

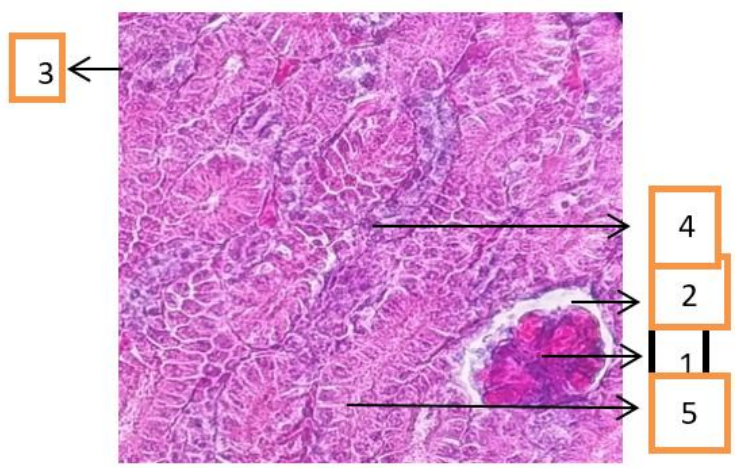

Figure 3. Anterior cross section of the kidney of Varanus salvator; Glomerulus (1), Bowman's capsule (2), Distal convoluted tubule (3), Medullary ray (4), Proximal convoluted tubule (5).

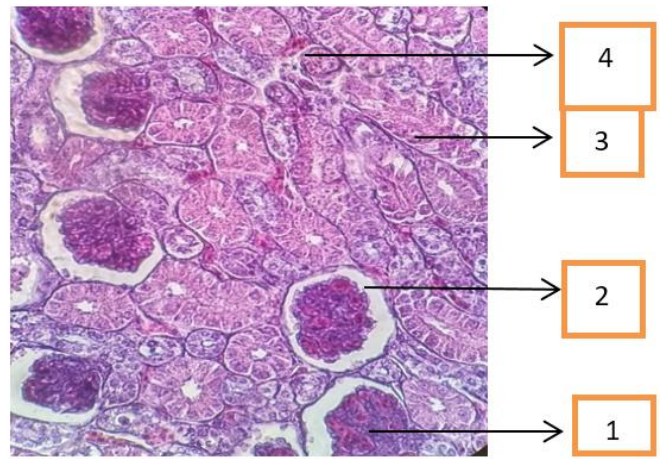

Figure 4. Middle cross section of the kidney of Varanus salvator; Glomerulus (1), Bowman's capsule (2), Proximal convoluted tubule (3), Distal convoluted tubule (4).

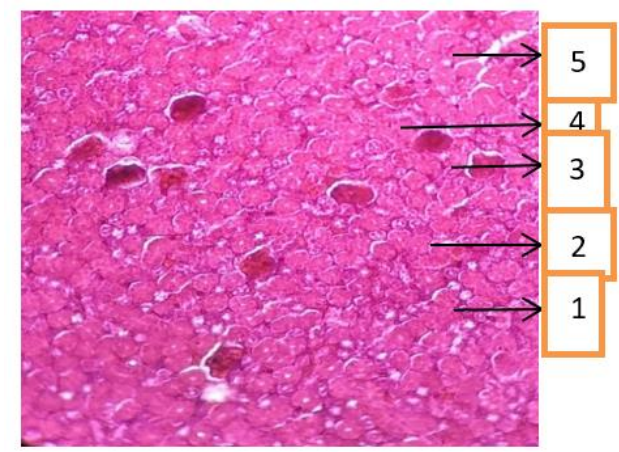

Figure 5. Posterior cross section of the kidney of Varanus salvator; Proximal convoluted tubule (1), Distal convoluted tubule (2), Glomerulus (3), Bowman's capsule (4). Lumen (5).

Based on research made microscopically on the cross section of the histological preparations of the monitor lizard (Varanus salvator, there are several parts including the anterior kidney, middle kidney, and posterior kidney. The kidney has distal contusus tubules, proximal tubule tubules, glomerulus, lumen and bowmen capsules. Glomerulus is located in the renal cortex, consisting of circular capillaries that receive blood from afferent and efferent arterioles, is a capillary anastomose surrounded by endothelial cells and fibrocytes, and blood filtrate will be excreted through proximal tubules. Tubules consist of proximal convoluted tubules (PCT), distal convoluted tubules. tubules (DCT), and collecting tubules (CT) that lead to the mesonephric duct (Kent, 1987).

Reptile kidneys have fewer nephrons than mammals and do not have the loop of Henle, so reptiles are unable to concentrate urine with higher osmolarity than plasma or are unable to produce concentrated urine. Urine will pass through mesonephric channels to the cloaca urodeum and then to the urinary bladder. The mesonephric duct has a transitional cube epithelium and transitional cylindrical epithelium which has a nucleus in the basal part of the cell (Guyton \& Hall 2006). The kidney type in Reptilia is methanephros. At the time of the embryo, Reptilia has a kidney type pronefros, then as an adult turns into mesonephros to methanephros. The 
result of excretion in Reptilia is gout. Uric acid is not too toxic when compared with ammonia produced by Mammalia. Gout can also be excreted without large volumes of water. Uric acid can be excreted in the form of a white paste. Some types of Reptiles also produce ammonia. For example, in crocodiles and turtles. Sea turtles that live in oceans have excretion glands to secrete the salt they contain in their bodies. This estuary gland is near the eyes. The resulting excretion is water containing salt (Guyton \& Hall 2006).

All lizards are uricotelic, that is, expressing uric acid as the main product of protein metabolism that is insoluble in water. Active uric acid is excreted by the proximal tubule and then transported by the mesonephric duct from each kidney to the urinary vein. Uric acid excretion functions to conserve water in the body and as an adaptation to a dry environment. Unlike the case with mammals, the significant excretion of ammonia and urea in reptiles depends on the environment in which they live and is seen only in reptiles that live in aquatic and semi-aquatic environments. Uric acid production is also compensated because reptiles cannot concentrate urine as in mammals, because reptiles do not have the loop of Henle (Guyton \& Hall 2006).

In vertebrates, the mechanism of the loop of Henle is affected by the mechanism of hormones that regulate blood circulation to the kidneys by constricting the diameter of the kidney capillaries. In a dehydrated state, this mechanism causes blood circulation to decrease in order to minimize the volume of filtered blood and water coming out of the nephron. In reptiles, kidney capillary constriction results in reduced blood supply to the nephrons so that the kidneys will experience necrose and eventually the reptiles die. Therefore, reptiles have an additional circulatory system known as the renal portal system, which is the route of blood flow from the caudal body to the kidneys before the heart (Koch, 2007).

\section{CONCLUSION}

Varanus salvator is known as the monitor lizard. This animal is a subspecies of Indonesian endemic monitor lizards which is only found in Java, Bali and Nusa Tenggara (except Timor Island). Varanus salvator kidney has a pair. Each kidney consists of cortex and medulla, with functional units are nephrons, consisting of renal corpuscles (Malpighi bodies), glomerulus, distal contus tubules, proximal tubule tubules, lumen and bowmen capsules. The kidneys are located in the caudodorsal abdomen. The kidneys play a role in the excretory system to excrete metabolic waste products.

\section{REFERENCES}

Bappenas. 1993. Biodiversity Action Plan for Indonesia. Ministry of Development Planning / National Development Planning Agency. Jakarta.

Guyton, A.C. 1991. Textbook of medical physiology (translated by Adji Dharma and P. Lukmanto). EGC. Jakarta.

Mahfud, et al. 2017. Morphology of Lizard Hemipenis (Varanus salvator bivittatus). Journal of Veterinary Science. Volume (35) No (1). Pp. 111-117.

Mardiastuti A, Soehartono T. 2003. Indonesian Reptile Trade in International Markets. Inside: T. Harvey, Editor. Amphibian and Reptile Conservation in Indonesia. Proceedings of the Seminar on Research Results of the Department of Forest Resources Conservation; 2003 May 8; Bogor, Indonesia. Bogor (ID): Bogor Agricultural University. pp. 131-144.

Suntoro, Handari. 1983. Coloring Methods (Histology and Histochemistry). Jakarta: Bhratara Karya Aksara.

Kent, Geeorge C. 1987. Comparative Anatomy of The Vertebrae. America: United States of America.

Koch A, Auliya M, Schmitz A, Kuch U, Böhme W. 2007. Morphological studies on the systematics of the South East Asian water monitors (Varanus salvator Complex): nominotypic populations and taxonomic overview. Mertensiella 16: 109-180. 
THIS PAGE INTENTIONALLY LEFT BLANK 